\title{
Mesoporous hollow carbon spheres for lithium-sulfur batteries: distribution of sulfur and electrochemical performance
}

\author{
Anika C. Juhl ${ }^{1}$, Artur Schneider ${ }^{2}$, Boris Ufer ${ }^{1}$, Torsten Brezesinski ${ }^{2}$, Jürgen Janek ${ }^{*} 2,3$ \\ and Michael Fröba*1
}

\section{Full Research Paper}

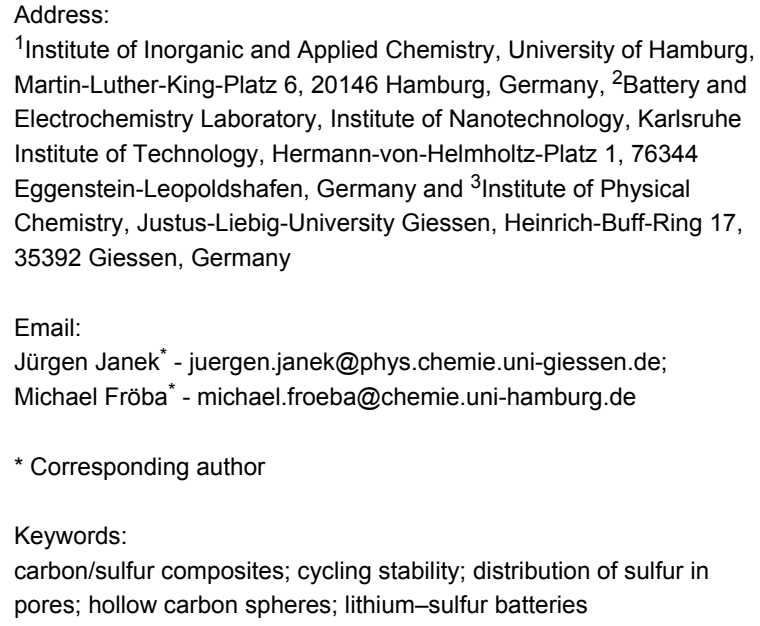

${ }^{1}$ Institute of Inorganic and Applied Chemistry, University of Hamburg, Martin-Luther-King-Platz 6, 20146 Hamburg, Germany, ${ }^{2}$ Battery and Electrochemistry Laboratory, Institute of Nanotechnology, Karlsruhe Institute of Technology, Hermann-von-Helmholtz-Platz 1, 76344 Eggenstein-Leopoldshafen, Germany and ${ }^{3}$ Institute of Physical Chemistry, Justus-Liebig-University Giessen, Heinrich-Buff-Ring 17, 35392 Giessen, Germany

\section{Email:}

Jürgen Janek ${ }^{*}$ - juergen.janek@phys.chemie.uni-giessen.de;

Michael Fröba* - michael.froeba@chemie.uni-hamburg.de

* Corresponding author

Keywords:

carbon/sulfur composites; cycling stability; distribution of sulfur in pores; hollow carbon spheres; lithium-sulfur batteries

Beilstein J. Nanotechnol. 2016, 7, 1229-1240.

doi:10.3762/bjnano.7.114

Received: 15 June 2016

Accepted: 18 August 2016

Published: 30 August 2016

This article is part of the Thematic Series "Advances in nanomaterials II".

Guest Editor: H. Hahn

(C) 2016 Juhl et al.; licensee Beilstein-Institut.

License and terms: see end of document.

\begin{abstract}
Hollow carbon spheres (HCS) with a nanoporous shell are promising for the use in lithium-sulfur batteries because of the large internal void offering space for sulfur and polysulfide storage and confinement. However, there is an ongoing discussion whether the cavity is accessible for sulfur. Yet no valid proof of cavity filling has been presented, mostly due to application of unsuitable high-vacuum methods for the analysis of sulfur distribution. Here we describe the distribution of sulfur in hollow carbon spheres by powder X-ray diffraction and Raman spectroscopy along with results from scanning electron microscopy and nitrogen physisorption. The results of these methods lead to the conclusion that the cavity is not accessible for sulfur infiltration. Nevertheless, HCS/ sulfur composite cathodes with areal sulfur loadings of $2.0 \mathrm{mg} \cdot \mathrm{cm}^{-2}$ were investigated electrochemically, showing stable cycling performance with specific capacities of about $500 \mathrm{mAh} \cdot \mathrm{g}^{-1}$ based on the mass of sulfur over 500 cycles.
\end{abstract}

\section{Introduction}

In the past 20 years, rechargeable lithium-ion batteries have proven to be superior energy storage devices and have been subject of intensive research [1-3]. However, being limited by a theoretical specific capacity of the active materials of approximately $300 \mathrm{mAh} \cdot \mathrm{g}^{-1}$, their storage capacity is not sufficient to serve as the primary energy source of domains such as long- 
range automotive transport $[4,5]$. Due to the high theoretical specific capacity $\left(1675 \mathrm{mAh} \cdot \mathrm{g}^{-1}\right)$ and specific energy $\left(2600 \mathrm{Wh} \cdot \mathrm{kg}^{-1}\right)$ of sulfur the lithium-sulfur $(\mathrm{Li}-\mathrm{S})$ battery is a promising candidate to overcome this limitation and, thus, replace the $\mathrm{Li}-$ ion system $[4,6]$. Besides, sulfur offers the advantages of being naturally abundant, non-toxic and of low cost.

Nevertheless, the Li-S cell is facing several problems that have to be settled for industrial application. One is the insulating nature of sulfur and its discharge product lithium sulfide $\left(\mathrm{Li}_{2} \mathrm{~S}\right)$, which leads to a low utilization of active material [7-9]. Another problem is the solubility of the lithium polysulfides $\left(\mathrm{Li}_{2} \mathrm{~S}_{x}, 3 \leq x \leq 8\right)$ formed as intermediate products during charge and discharge in the commonly used organic electrolytes. The dissolved polysulfides shuttle between the cathode and anode and cause the deposition of insoluble $\mathrm{Li}_{2} \mathrm{~S}_{2}$ and $\mathrm{Li}_{2} \mathrm{~S}$ on both upon further reduction at the end of discharge. In consequence, the cell suffers from low Coulombic efficiency and short cycle life $[8,10,11]$. The third drawback is a volume expansion of about $80 \%$ during discharge, resulting from the lower density and thus higher molar volume of lithium sulfide (28.0 $\mathrm{cm}^{3} \cdot \mathrm{mol}^{-1}$ compared to $15.5 \mathrm{~cm}^{3} \cdot \mathrm{mol}^{-1}$ for sulfur) [12] This can lead to the loss of electrical contact of $\mathrm{Li}_{2} \mathrm{~S}$ with the conducting additive or the current collector [9].

Cathode materials composed of porous carbon and sulfur show promising results with regard to overcoming these problems. Thus, a lot of research has been carried out on nanostructured carbon hosts for sulfur storage including carbon fibers [13,14], carbon nanotubes [15,16], graphene/graphene oxide [17-19] as well as micro-/mesoporous carbons [20-22]. Among the porous carbons, especially hollow carbon spheres (HCS) have attracted significant attention because sulfur and the resulting polysulfides can be confined in the shell while the large cavity offers room for sulfur storage and volume expansion during discharge [23-31].

However, there is an ongoing discussion on the location of sulfur in the hollow spheres. It remains unclear at present, whether the cavity and the micro- or mesopores of the shell are both accessible for sulfur infiltration. The analysis of sulfur dis- tribution in the literature is usually conducted by energy dispersive X-ray spectroscopy (EDX) measurements using either a transmission electron microscope (TEM) or a scanning electron microscope (SEM). Although revealing similarities in the main characteristics, the conclusions being drawn are rather contradictory [24-31]. A problem may arise from the high spatial mobility of sulfur species under vacuum conditions. Raiß et al. examined the behavior of sulfur in the presence of carbon in high vacuum and found that sulfur is redistributing rapidly. They concluded that for this reason, the analysis of carbon/ sulfur composites by means of vacuum-based methods can be misleading [32].

In this work, we present the analysis of sulfur distribution in hollow carbon spheres with a mesoporous shell by combining the results from non-vacuum methods, namely X-ray diffraction (XRD) and Raman spectroscopy, with those from vacuumbased ones (SEM and nitrogen physisorption). Moreover, we examined the influence of the pressure during melt impregnation on the distribution of sulfur and compared the resulting loading and distribution with composites obtained by impregnation from a solution of sulfur in carbon disulfide. Finally, the electrochemical performance of $\mathrm{HCS} /$ sulfur composite cathodes with a sulfur areal loading of $2.0 \mathrm{mg} \cdot \mathrm{cm}^{-2}$ was investigated.

\section{Results and Discussion \\ Silica template and hollow carbon spheres}

Hollow carbon spheres with a mesoporous shell were obtained by impregnation of silica spheres with a core-shell structure with phenol and formaldehyde (first step in Figure 1). Carbonization under inert atmosphere and etching of the template yielded the hollow spheres (second and third step in Figure 1).

The employed silica spheres with a solid core and mesoporous shell (SCMS silica) were synthesized in two steps by modified literature methods $[33,34]$. Solid silica spheres were synthesized by the Stöber method [35]. In the second step a mesoporous shell was grown on the spheres by employing tetraethyl orthosilicate in presence of cetyltrimethylammonium bromide $(\mathrm{CTAB})$ as a structure-directing agent. Combustion of CTAB in

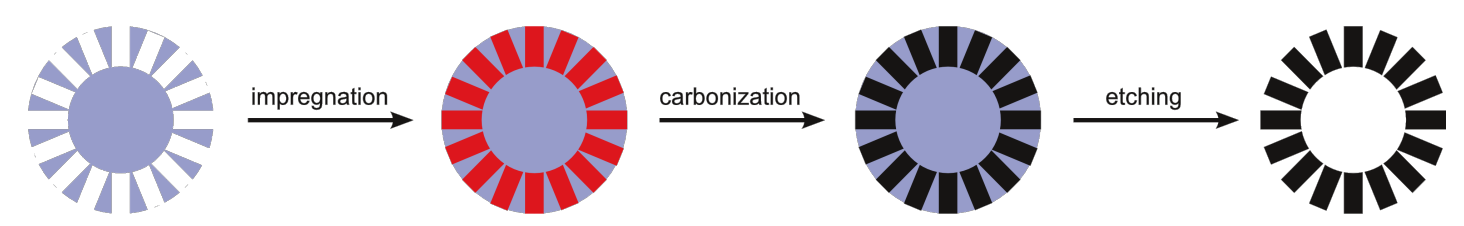

Figure 1: Synthesis of the hollow carbon spheres via impregnation of silica spheres with solid core and mesoporous shell, followed by carbonization and etching of silica. 
air generated the core-shell silica spheres. The diameter of the solid core was determined to be $380 \mathrm{~nm}$ by dynamic light scattering, while the diameter of the core-shell particles was about $515 \mathrm{~nm}$. From SEM images (Figure S1 in Supporting Information File 1) a diameter of about $490 \mathrm{~nm}$ was determined for the core-shell spheres. Further characterization of the SCMS silica can be found in Supporting Information File 1 (Figure S2).

SEM and TEM images of HCS synthesized from SCMS silica (Figure 2) show that the particle size is uniform with an outer diameter of approximately $400 \mathrm{~nm}$, an inner diameter of about $300 \mathrm{~nm}$ and a shell thickness of roughly 40 to $50 \mathrm{~nm}$. Moreover, the shell of the HCS has an appearance typical of a material composed of disordered mesopores. The disordered structure is supported by the small-angle X-ray diffraction pattern of the hollow spheres (Figure $3 \mathrm{a}$ ), which does not show any reflections between $2 \theta=0.5^{\circ}$ and $2 \theta=10^{\circ}$.

The wide-angle X-ray diffraction pattern (Figure 3b) shows two broad reflections that result from the interlayer and intralayer scattering of graphene sheets. From the fact that they are broad and little pronounced it can be concluded that the degree of graphitization is low and the carbon is mainly amorphous [36,37]. This is confirmed by the Raman spectrum (Figure 3c), which shows two bands centered at $1597 \mathrm{~cm}^{-1}$ (G band) and $1340 \mathrm{~cm}^{-1}$ (D band) typical of carbon with small graphitic domains. The $\mathrm{G}$ band results from the in-plane stretching of $\mathrm{sp}^{2}$-bonded (graphitic) carbon atoms, while the $\mathrm{D}$ band is induced by defects and disorder in the carbon structure [38].

From the nitrogen physisorption isotherm (Figure $4 \mathrm{a}$ ) of the HCS a Brunauer-Emmet-Teller (BET) surface of $1123 \mathrm{~m}^{2} \cdot \mathrm{g}^{-1}$ can be determined. The pore size distribution (Figure $4 \mathrm{~b}$ ) was calculated by a quenched solid density functional theory (QSDFT) model from the adsorption branch and shows that the mesopore diameter of the spheres is approximately $5 \mathrm{~nm}$. The adsorbed volume of nitrogen gas is not reaching a plateau at high relative pressures but is increasing steeply at a pressure of $p / p_{0}$ higher than 0.9 . This is because of the large inner cavity of the hollow spheres, the volume of which cannot be determined

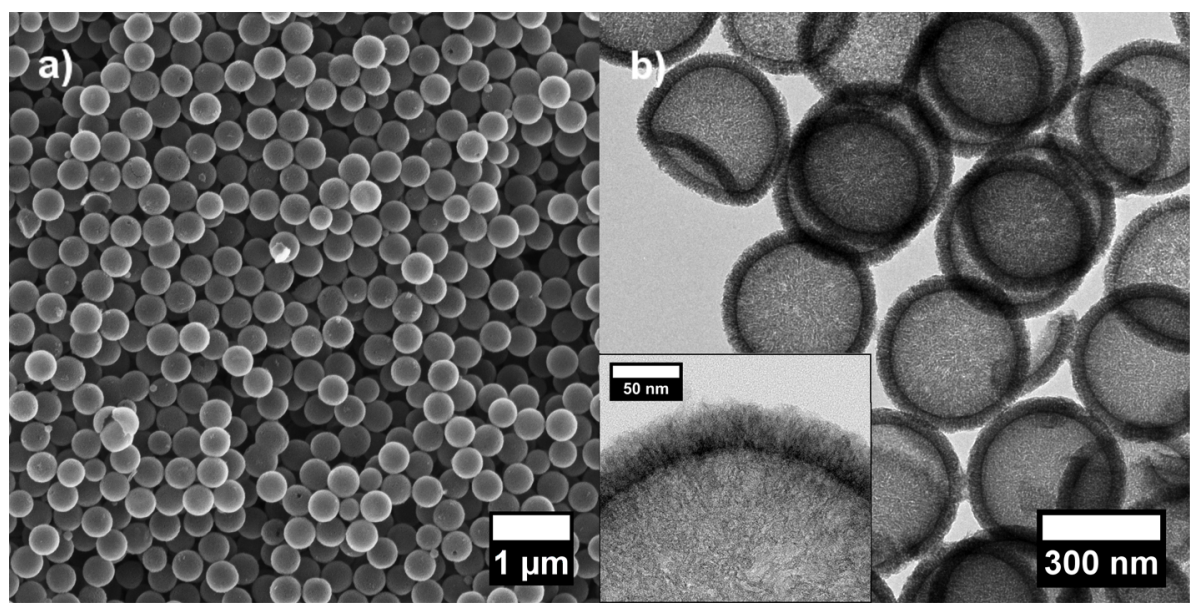

Figure 2: a) SEM and b) TEM images of mesoporous hollow carbon spheres. Inset: larger magnification of the shell of a hollow sphere.
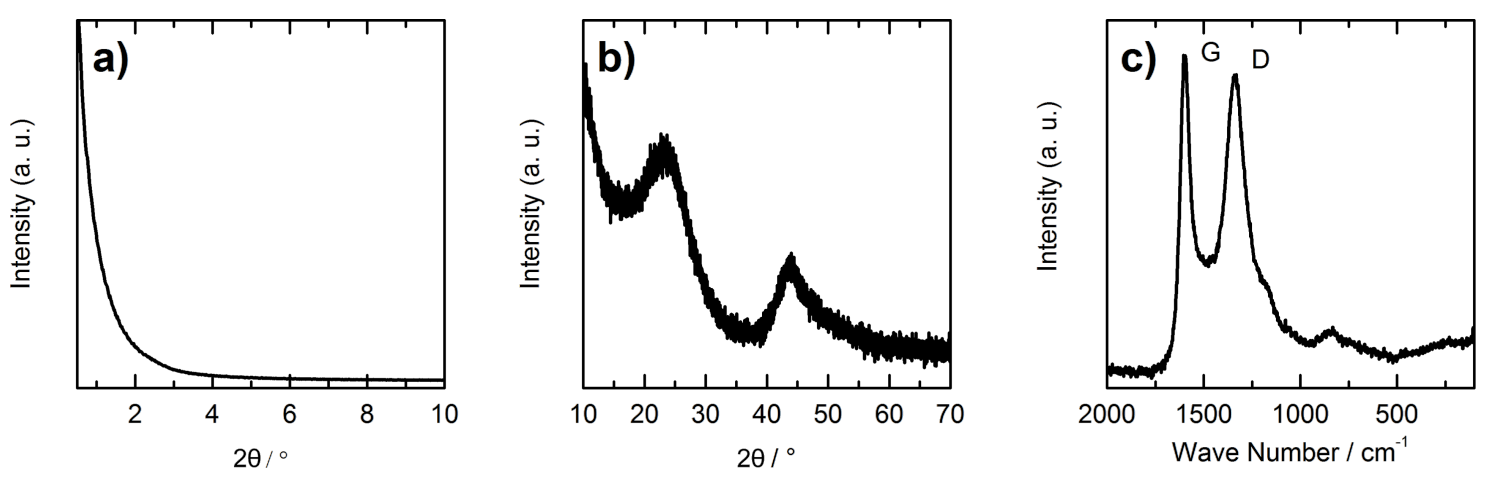

Figure 3: a) Small-angle and b) wide-angle XRD patterns as well as c) Raman spectrum of hollow carbon spheres. 

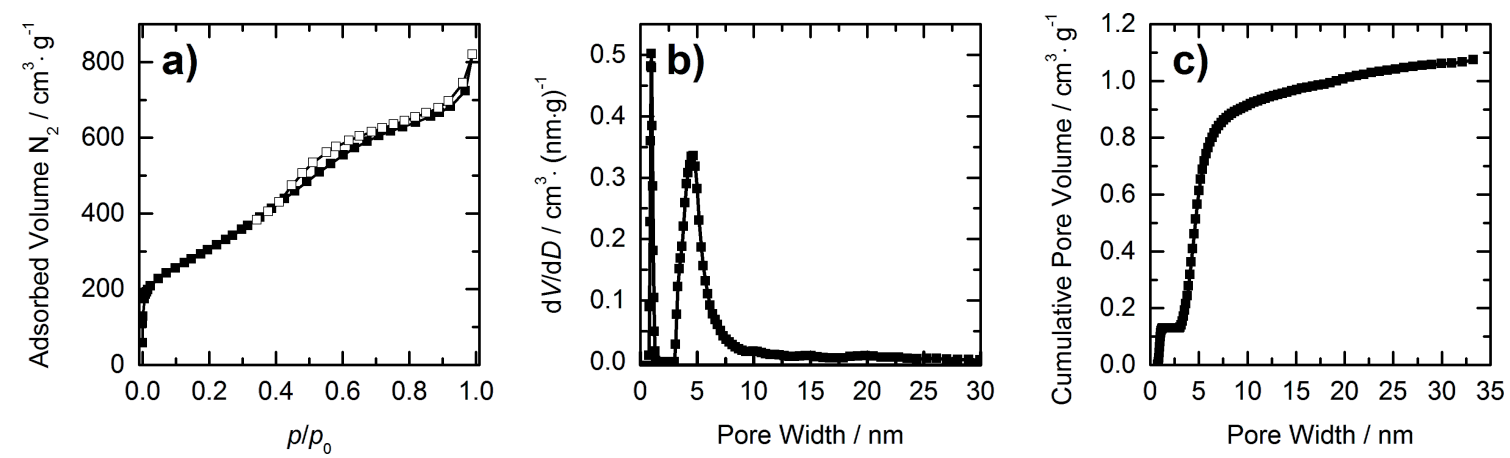

Figure 4: a) Nitrogen physisorption isotherm (measured at $77 \mathrm{~K}$ ), b) pore size distribution and c) cumulative pore volume of hollow carbon spheres Pore size distribution and cumulative pore volume were obtained from the isotherm by QSDFT analysis.

by nitrogen physisorption. And this in turn makes it impossible to determine the total pore volume of the HCS [39]. To assess the pore volume of the shell, however, the cumulative pore volume (Figure $4 \mathrm{c}$ ) of pores in the meso-range can be used as an estimate. As the shell thickness is about $40 \mathrm{~nm}$, it can be assumed that the pore volume of the shell originates from pores smaller than that. To be sure not to take into account too much of the cavity volume, the pore volume of the shell was estimated from the cumulative pore volume of pores up to $30 \mathrm{~nm}$, which adds up to $1.06 \mathrm{~cm}^{3} \cdot \mathrm{g}^{-1}$. The micropores (pores smaller than $2 \mathrm{~nm}$ ) contribute $0.13 \mathrm{~cm}^{3} \cdot \mathrm{g}^{-1}$ to this volume.

The microporosity of carbonaceous materials can be determined more appropriately by carbon dioxide physisorption. From carbon dioxide physisorption measurements (see Figure S3 in Supporting Information File 1 for the isotherm, pore size distribution and cumulative pore volume) it can be concluded that the HCS contain a considerable amount of pores smaller than $1.5 \mathrm{~nm}$. The cumulative pore volume of these small pores is as high as $0.26 \mathrm{~cm}^{3} \cdot \mathrm{g}^{-1}$, which is significantly higher than the $0.13 \mathrm{~cm}^{3} \cdot \mathrm{g}^{-1}$ determined by nitrogen physisorption for pores smaller than $2 \mathrm{~nm}$.

\section{Carbon/sulfur composites}

To get an impression of how much sulfur can be loaded into the pores and the cavities of the hollow carbon spheres, we calculated which sulfur loadings can be reached by either filling only the pores of the shell of the HCS or by filling the pores of the shell and the cavity.

The maximum mass of sulfur $m_{\text {sulfur }}$ that can be incorporated into the shell by melt impregnation can be calculated by multiplication of the pore volume $V_{\text {pores }}$ of the shell $\left(1.06 \mathrm{~cm}^{3}\right.$ for $1 \mathrm{~g}$ HCS $)$ with the density of liquid sulfur $\left(\rho_{\text {sulfur }}=1.819 \mathrm{~g} \cdot \mathrm{cm}^{-3}\right)$ [12].

$$
m_{\text {sulfur }}=V_{\text {pores }} \cdot \rho_{\text {sulfur }}
$$

This means, that by filling just the shell of HCS, $1.93 \mathrm{~g}$ sulfur can be loaded into $1 \mathrm{~g}$ of HCS, corresponding to a sulfur loading $w_{\text {sulfur }}$ of $65 \mathrm{wt} \%$. The latter value was calculated by using Equation 2, where $m_{\mathrm{HCS}}$ is the mass of the hollow carbon spheres.

$$
w_{\text {sulfur }}=\frac{m_{\text {sulfur }}}{m_{\text {sulfur }}+m_{\mathrm{HCS}}}
$$

The maximum sulfur loading for the case that both the cavity and the shell of HCS are filled by sulfur can also be calculated when considering the pore volume of the shell $V_{\text {pores }}$ and the volume of the cavities by taking into account the geometry of a sphere. The derivation of the resulting Equation 3 can be found in Supporting Information File 1. The constant $C$ is given by Equation 4.

$$
\begin{gathered}
w_{\text {sulfur }}=\frac{C \cdot \rho_{\text {sulfur }}}{C \cdot \rho_{\text {sulfur }}+m_{\mathrm{HCS}}} \\
C=\left(\frac{m_{\mathrm{HCS}}}{\rho_{\text {carbon }}}+V_{\text {pores }}\right) \frac{r_{\mathrm{i}}^{3}}{r_{\mathrm{o}}^{3}-r_{\mathrm{i}}^{3}}+V_{\text {pores }}
\end{gathered}
$$

In Equation 4, $\rho_{\text {carbon }}$ represents the density of carbon without pores, $r_{\mathrm{i}}$ is the radius of the cavity (the inner radius of the hollow sphere) and $r_{\mathrm{o}}$ is the outer radius of the sphere.

Because the maximum sulfur loading by melt impregnation is calculated, the density of liquid sulfur is used again. The density of the carbon is unknown, but as the HCS are obtained 
by carbonization at $900{ }^{\circ} \mathrm{C}$ and the XRD pattern indicates mainly amorphous carbon, the density of amorphous carbon $\left(\rho_{\text {amorphousC }}=1.8 \mathrm{~g} \cdot \mathrm{cm}^{-3}\right)$ [12] is assumed. This way a sulfur loading of $81 \mathrm{wt} \%$ is obtained. For comparison, the possible sulfur loadings were also determined using the densities of graphite $\left(\rho_{\text {graphite }}=2.30 \mathrm{~g} \cdot \mathrm{cm}^{-3}\right)$ [12] and charcoal $\left(\rho_{\text {charcoal }}=0.56 \mathrm{~g} \cdot \mathrm{cm}^{-3}\right)[12]$. These calculations led to values of $80 \mathrm{wt} \%$ and $86 \mathrm{wt} \%$, respectively. Consequently, it can be concluded that a sulfur loading between $80 \mathrm{wt} \%$ and $86 \mathrm{wt} \%$ can be reached by filling both the shell and the cavity of HCS with sulfur.

To monitor the filling of the hollow spheres, they were loaded with sulfur in mass ratios of carbon to sulfur ranging from $70: 30$ to $30: 70$ by a melt impregnation method at $155{ }^{\circ} \mathrm{C}$. For comparison, samples with sulfur loadings of $60 \mathrm{wt} \%$ and $70 \mathrm{wt} \%$ were also prepared in vacuum and under increased pressure. Moreover, impregnation of HCS with sulfur from a solution containing sulfur in carbon disulfide was carried out repeatedly so that sulfur loadings close to 60 and $70 \mathrm{wt} \%$ were obtained. The mass fractions of carbon and sulfur in the composites were determined by thermogravimetric measurements (see Figure S5 in Supporting Information File 1) and the corresponding values are given in Table 1. Samples are denoted as HCS- $x$-method, where $x$ indicates the exact amount of sulfur and method specifies the impregnation method. The term "melt" stands for melt impregnation at ambient pressure, "vac" for melt impregnation in vacuum, "press" indicates impregnation under increased pressure and "sol" stands for the impregnation from solution. It is worth noting that even the composite with the highest fraction of sulfur (HCS-76-sol) contains less sulfur than can theoretically be filled into the pore volume of cavity and shell, which would be at least $80 \mathrm{wt} \%$ (see calculations above).

\section{X-ray diffraction}

The HCS/sulfur composites were investigated by powder X-ray diffraction (pXRD). The wide-angle XRD patterns of the samples impregnated at ambient pressure (Figure 5a) show that up to a sulfur content of $60 \mathrm{wt} \%$ there are only the broad reflections of amorphous carbon visible. In the literature this behavior is attributed to sulfur being dispersed in mesopores, thereby losing its crystallinity $[22,40]$. For a sulfur content of $70 \mathrm{wt} \%$ however, reflections of crystalline sulfur can be seen. For the samples impregnated with sulfur in vacuum (Figure 5b), under increased pressure (Figure 5c) and from solution (Figure 5d), the XRD patterns look similar: For a sulfur content of less than $60 \mathrm{wt} \%$ no reflections are visible, while diffraction peaks of crystalline sulfur can be observed when the sulfur content is approximately $70 \mathrm{wt} \%$.

There are two possible explanations for the existence of crystalline sulfur in the composites. The first is that sulfur fills the cavities of the HCS leading to larger crystallites than in the mesopores of the shell. The second explanation is that sulfur accumulates on the outside of the hollow spheres, thus showing bulk-like behavior. Given that no broadening of the sulfur reflections due to nano-sized crystallites can be observed, we conclude that the crystalline sulfur is only present on the outside of HCS.

\begin{tabular}{|c|c|c|c|c|}
\hline sample & water content / \% & sulfur content / \% & carbon content / \% & residual mass / $\%$ \\
\hline $\mathrm{HCS}$ & 2.3 & - & 96.0 & 2.0 \\
\hline elemental sulfur & - & 99.5 & - & 0.6 \\
\hline HCS-29-melt & 1.0 & 29.2 & 68.3 & 1.9 \\
\hline HCS-38-melt & 0.6 & 37.9 & 60.6 & 0.8 \\
\hline HCS-49-melt & - & 48.6 & 50.5 & 0.5 \\
\hline HCS-59-melt & 0.2 & 59.1 & 39.2 & 1.5 \\
\hline HCS-68-melt & - & 68.3 & 30.1 & 1.6 \\
\hline HCS-58-vac & - & 58.0 & 41.2 & 1.0 \\
\hline HCS-67-vac & - & 66.5 & 31.7 & 2.3 \\
\hline HCS-59-press & - & 58.8 & 39.5 & 1.2 \\
\hline HCS-67-press & - & 67.2 & 31.2 & 2.2 \\
\hline HCS-53-sol ${ }^{b}$ & - & 53.0 & 45.4 & 1.2 \\
\hline HCS-76-sol ${ }^{b}$ & - & 76.0 & 23.0 & 1.7 \\
\hline
\end{tabular}

a Values that add up to more than $100 \%$ are due to the measuring inaccuracy of thermogravimetry.

bMass ratios obtained by impregnation from solution differ from those obtained by the other methods because carbon disulfide evaporated fast, thus changing the concentration of the solution. 

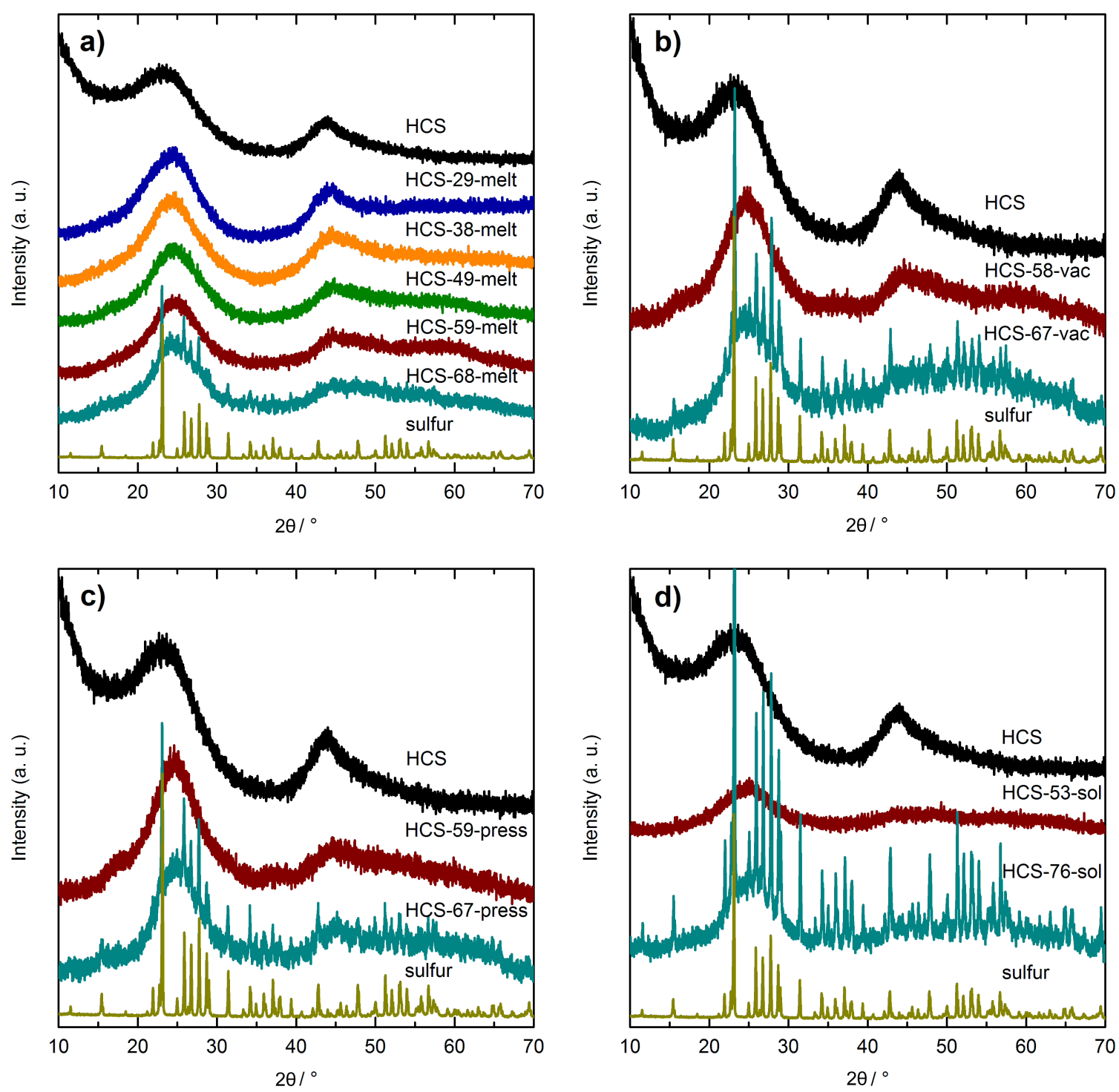

Figure 5: Powder X-ray diffraction patterns of HCS loaded with different amounts of sulfur by a) melt impregnation at ambient pressure, b) melt impregnation in vacuum, c) melt impregnation under increased pressure and d) impregnation from a solution of sulfur in carbon disulfide.

\section{Raman spectroscopy}

Raman spectroscopy (Figure 6) shows results similar to those obtained by pXRD measurements. For carbon/sulfur composites with sulfur contents below $60 \mathrm{wt} \%$, the characteristic bands resulting from the vibrations of $\mathrm{S}_{8}$ cannot be observed, while they are visible at least in some of the composites containing more than $60 \mathrm{wt} \%$ sulfur. This behavior has also been reported in the literature [41-43] but could not yet be explained satisfactorily. However, as these observations are in good agreement with the results from pXRD, it can be assumed, that the lack of Raman bands might also be due to confinement effects. Thus, the appearance of bands at high sulfur loadings could also be explained either by sulfur filling the cavities of HCS or by sulfur accumulating on the outside of the spheres.

\section{SEM and EDX}

SEM images of HCS-58-vac and HCS-67-vac (Figure 7a,b) which can be seen as representative examples of the composites studied here (see Figure S6 and Figure S7 in Supporting Information File 1 for the others), show that the sample morphology is significantly different depending on the sulfur content. SEM images of samples containing less than $60 \mathrm{wt} \%$ sulfur only show carbon spheres regardless of the impregnation method. SEM images of the composites containing $67 \mathrm{wt} \%$ sulfur or more indicate the presence of a second phase. This phase is darker than the spheres and is extended over large areas. Exemplary, EDX measurements of the hollow spheres and the second phase in HCS-67-vac are shown in Figure 7c; the measured areas and corresponding EDX spectra are marked 

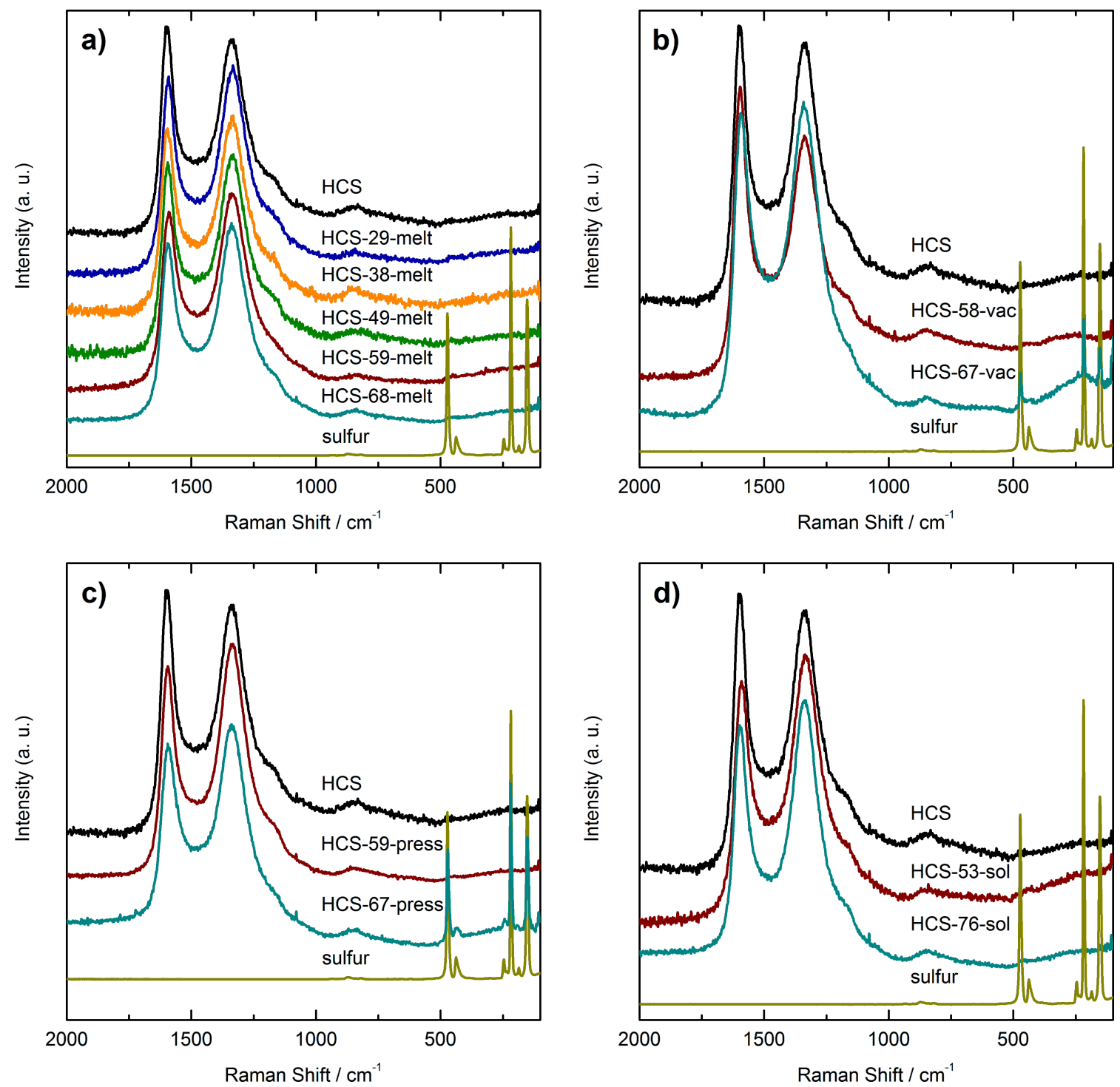

Figure 6: Raman spectra of HCS loaded with different amounts of sulfur by a) melt impregnation at ambient pressure, b) melt impregnation in vacuum, c) melt impregnation under increased pressure and d) impregnation from a solution of sulfur in carbon disulfide.
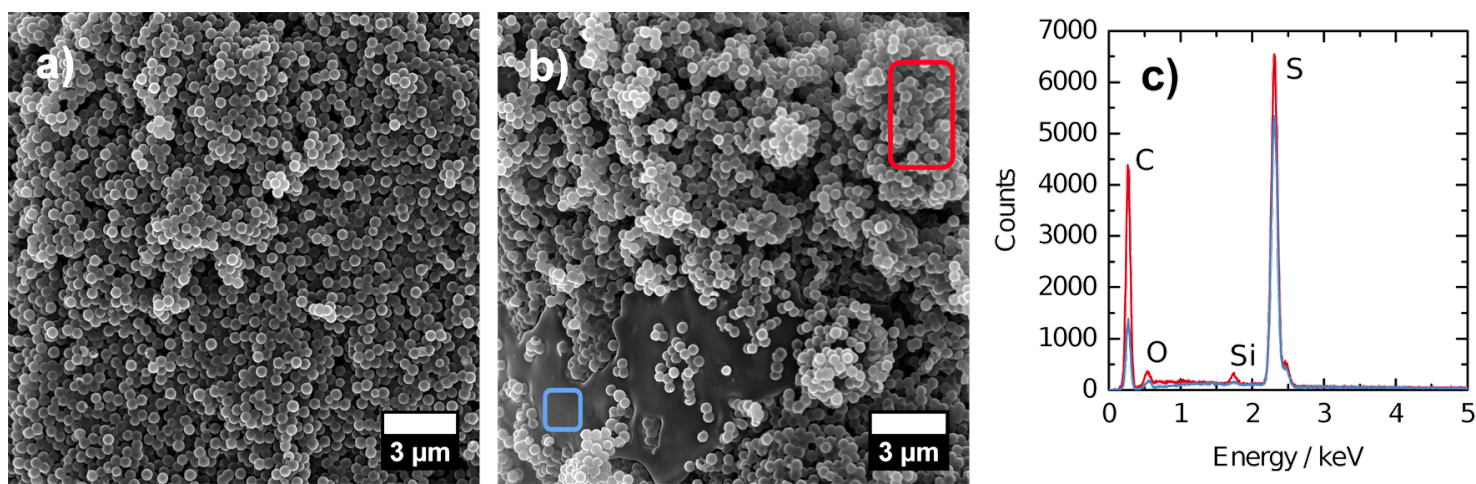

Figure 7: SEM images of a) HCS-58-vac, b) HCS-67-vac, and c) EDX spectra of HCS-67-vac (measured areas are marked red and blue, respectively). 
in red and blue. When comparing the EDX peaks of sulfur and carbon in both areas, it can be clearly seen that there is a larger amount of sulfur present in the darker areas than in the sulfurloaded HCS. Thus, it can be assumed that the second phase consists of molten and recrystallized sulfur. The amount of carbon that is still measureable in this area is due to the deposition of an additional carbon layer onto the samples prior to EDX analysis. EDX spectra for HCS-68-melt, HCS-67-press and HCS-76-sol can be found in Supporting Information File 1 (Figure S7). As these large accumulations of sulfur can only be found in samples with the highest sulfur contents, we assume that this result is not due to sulfur redistribution in vacuum during the SEM/EDX analysis. It also helps to explain the appearance of sulfur reflections in pXRD and characteristic sulfur bands in the Raman spectra. Keeping in mind that the shell of HCS is supposed to hold about $66 \mathrm{wt} \%$ sulfur while the complete hollow spheres should be able to contain as much as 80 wt \% sulfur, we conclude from the results with pXRD, Raman spectroscopy and SEM/EDX that only the shell of HCS can be filled by sulfur. Using more sulfur to eventually fill the cavity leads to crystalline sulfur on the outside of HCS.

\section{Nitrogen physisorption}

Nitrogen physisorption measurements of the composites also confirm the inaccessibility of the HCS cavity for sulfur. Nevertheless, the results have to be handled with care because of the vacuum applied while degassing and measuring the samples. From the physisorption isotherms the pore volume of the shell of the HCS/sulfur composites can be determined in the same way as that of the pure hollow spheres (see Figure S8 in Supporting Information File 1 for the physisorption isotherms and plots of cumulative pore volumes). For comparison, a theoretical pore volume can be calculated from the pore volume of HCS and the volume of the impregnated sulfur according to Equation 5 (for the derivation see Supporting Information File 1). The density of liquid sulfur was used for the calculation of the theoretical pore volumes because both the state and structure of sulfur in nanopores are unknown.

$$
V_{\text {pores,C-S }}=\frac{V_{\text {pores, } \mathrm{HCS}} \cdot m_{\mathrm{HCS}}-\frac{m_{\text {sulfur }}}{\rho_{\text {sulfur }}}}{m_{\mathrm{HCS}}+m_{\text {sulfur }}}
$$

The calculation was carried out for all samples containing less than $60 \mathrm{wt} \%$ sulfur as the others contain a sulfur volume higher than the pore volume of the shell. Table 2 gives the pore volumes of HCS and HCS/sulfur composites determined from nitrogen physisorption and the calculated pore volumes. Interestingly, the measured pore volume is always lower than the calculated value. This might be due to the fact that some pores are blocked by sulfur and thus, are no longer accessible for nitrogen gas during the measurements. We believe that the strong capillary forces on liquids/melts in the mesopores are responsible for the pore blocking effect. Once sulfur has filled the mesopores there is no further driving force for filling of the cavities, and only the mesoporous shell is filled with sulfur.

\section{Electrochemical characterization}

Since we could show that, for a HCS/sulfur ratio of approximately 40:60, the sulfur is completely incorporated in the porous carbon, electrochemical testing was performed on cointype cells using HCS/sulfur composite containing $61 \mathrm{wt} \%$ sulfur as cathode material. The voltage range was $2.5-1.7 \mathrm{~V}$ with respect to $\mathrm{Li} / \mathrm{Li}^{+}$. Representative charge-discharge curves for the first, 100th and 500th cycles of a cell with areal sulfur loading of $2.0 \mathrm{mg} \cdot \mathrm{cm}^{-2}$ are shown in Figure $8 \mathrm{a}$. This intermediate loading was chosen in order to ensure competitive areal capacities. Moreover, electrodes with higher sulfur loadings, especially with increased electrode thickness are prone to severe degradation, as the mechanical stress and the interfacial resistance are increased. Two distinct plateaus at about $2.3 \mathrm{~V}$ and $2.1 \mathrm{~V}$ are clearly visible upon discharge, corresponding to the reduction of elemental sulfur to higher-order lithium polysulfides $\left(\mathrm{Li}_{2} \mathrm{~S}_{x}\right.$ with $\left.6 \leq x \leq 8\right)$ and formation of lower-order lithium polysulfide species $\left(\mathrm{Li}_{2} \mathrm{~S}_{y}\right.$ with $\left.2 \leq y \leq 6\right)$ and $\mathrm{Li}_{2} \mathrm{~S}$, respectively. The plateau at $1.8 \mathrm{~V}$ in the first discharge cycle at $\mathrm{C} / 50$

\begin{tabular}{|c|c|c|}
\hline sample & measured pore volume $/ \mathrm{cm}^{3} \cdot \mathrm{g}^{-1}$ & theoretical pore volume $/ \mathrm{cm}^{3} \cdot \mathrm{g}^{-1}$ \\
\hline HCS & 1.06 & - \\
\hline HCS-29-melt & 0.57 & 0.58 \\
\hline HCS-38-melt & 0.39 & 0.44 \\
\hline HCS-49-melt & 0.23 & 0.27 \\
\hline HCS-59-melt & 0.08 & 0.09 \\
\hline HCS-58-vac & 0.07 & 0.12 \\
\hline HCS-59-press & 0.08 & 0.10 \\
\hline HCS-53-sol & 0.17 & 0.19 \\
\hline
\end{tabular}


rate can be ascribed to lithium nitrate decomposition at the cathode side [44]. The charge curve shows two plateaus at about $2.2 \mathrm{~V}$ and $2.4 \mathrm{~V}$, indicating the reoxidation of lithium polysulfides to sulfur. Figure $8 \mathrm{~b}$ presents data on the long term performance at $\mathrm{C} / 5$. As can be seen, the specific capacity (areal capacity) levels off at about $500 \mathrm{mAh} \cdot \mathrm{g}^{-1}\left(1 \mathrm{mAh} \cdot \mathrm{cm}^{-2}\right)$ after 60 cycles, and the cell exhibits rather stable performance for 500 cycles with a fade rate of $0.06 \%$ per cycle (between the 2 nd and 500th cycle at $\mathrm{C} / 5$ ). Also, the Coulombic efficiency stabilizes above $99.5 \%$, thereby indicating good reversibility.
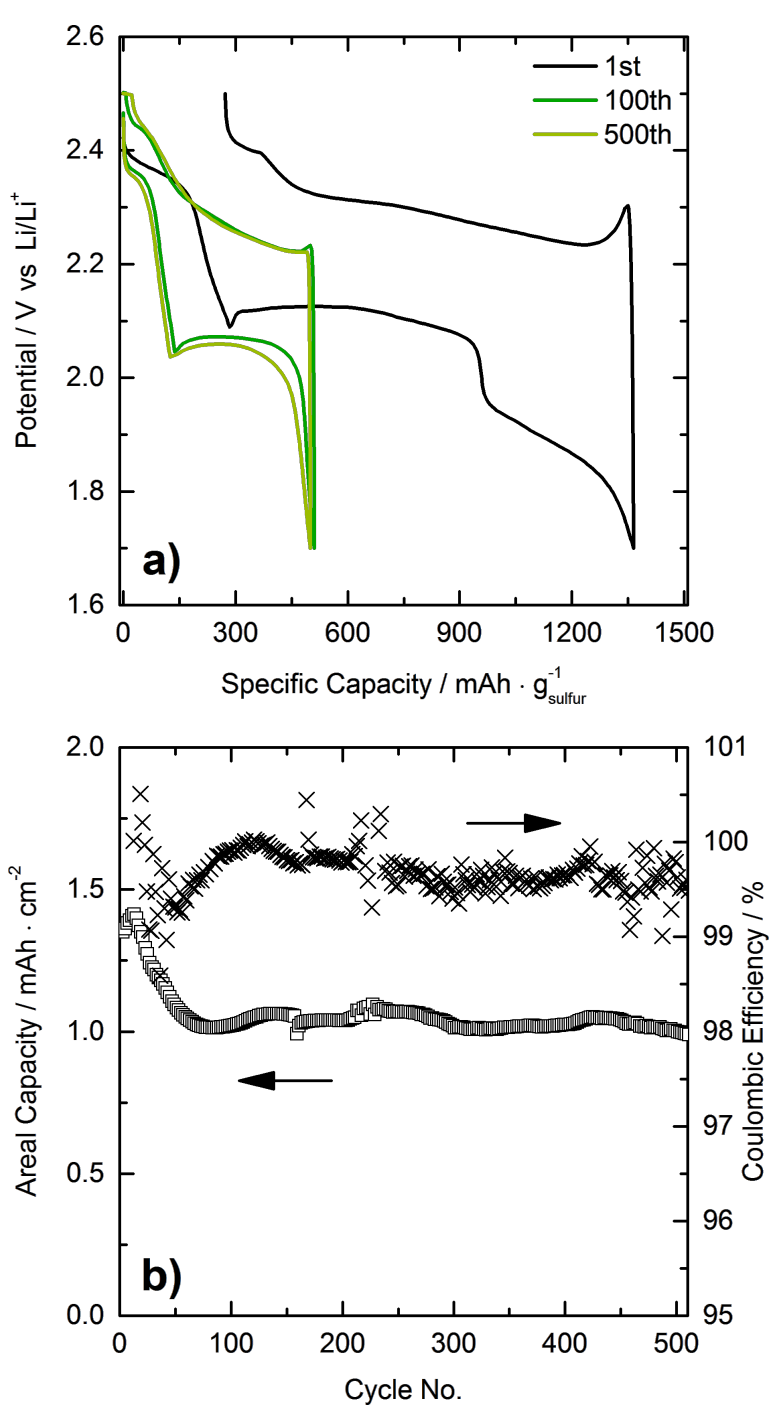

Figure 8: a) Voltage profiles of a Li-S cell with areal sulfur loading of $2.0 \mathrm{mg} \cdot \mathrm{cm}^{-2}$. After the formation cycle at $\mathrm{C} / 50$, the rate was increased to $C / 5$. b) Areal capacity and Coulombic efficiency versus the cycle number. The 1 st cycle areal capacity was about $2.8 \mathrm{mAh} \cdot \mathrm{cm}^{-2}$.

The measured areal capacities are comparable with those calculated from literature data $[24,27,29]$. Nevertheless, due to differ- ences in cell type, electrode and electrolyte composition as well as electrolyte/sulfur ratio, a precise comparison is not possible. Even more, as necessary information for this comparison like the electrolyte/sulfur ratio and partly also the areal sulfur loading are often not given.

Overall, the data in Figure 8 demonstrate that Li-S cells based on HCS/sulfur composite show good cyclability, with moderate specific capacities at $\mathrm{C} / 5$ rate. Given that the results were obtained on non-optimized cathodes, this is a good starting point for future research in this direction.

\section{Conclusion}

Hollow carbon spheres with a mesoporous shell were loaded with different amounts of sulfur by melt impregnation at ambient pressure, in vacuum and under increased pressure as well as from a solution of sulfur in carbon disulfide. By combining calculations considering the mesopore volume of the shell and the size of the cavity with results from pXRD, Raman spectroscopy and SEM, it could be concluded that the cavity of HCS is not filled by sulfur regardless of the impregnation method. This is an important result as the analysis of HCS/ sulfur composites is usually carried out by EDX measurements during which sulfur can redistribute due to the vacuum applied. Although the cavity of the HCS remains empty during sulfur loading, batteries using HCS/sulfur composite with $61 \mathrm{wt} \%$ sulfur and with reasonably high sulfur loading of $2.0 \mathrm{mg} \cdot \mathrm{cm}^{-2}$ showed stable electrochemical performance over 500 cycles. It seems possible that the empty cavity has a positive effect on polysulfide confinement. In summary, the HCS employed in this work are a promising system capable of storing and retaining significant amounts of sulfur, thus ensuring stable performance upon prolonged cycling.

\section{Experimental details}

\section{Synthesis of hollow carbon spheres Synthesis of silica template}

Silica spheres with a solid core and mesoporous shell were synthesized according to a modification of literature methods in a two-step procedure [33,34]. For synthesis of the core, $536 \mathrm{~mL}$ of ethanol were mixed with $45 \mathrm{~mL}$ of aqueous ammonia (32\%) and $6.8 \mathrm{~mL}$ of deionized water. After stirring for $30 \mathrm{~min}, 24 \mathrm{~mL}$ of tetraethyl orthosilicate (TEOS) were added and the mixture was stirred at room temperature for $18 \mathrm{~h}$. The resulting suspension was diluted with $1200 \mathrm{~mL}$ of deionized water and $180 \mathrm{~mL}$ of a solution of cetyltrimethylammonium bromide $(0.11 \mathrm{~mol} / \mathrm{L}$ in a 2:1 mixture of water and ethanol) was added. The suspension was stirred at room temperature for one hour before $13.5 \mathrm{~mL}$ of TEOS were added dropwise. After stirring for another $18 \mathrm{~h}$ at room temperature, the suspension was neutralized with hydrochloric acid (32\%) to precipitate the core-shell 
particles. The precipitate was centrifuged and dried at $60{ }^{\circ} \mathrm{C}$ before removing the surfactant by calcination at $550{ }^{\circ} \mathrm{C}$ for $6 \mathrm{~h}$ in air.

\section{Synthesis of hollow carbon spheres}

The synthesis of hollow carbon spheres was carried out by a combination and modification of literature methods $[45,46]$. Phenol $(3.52 \mathrm{~g})$ was melted at $45^{\circ} \mathrm{C}$ and $615 \mu \mathrm{L}$ of a $20 \mathrm{wt} \%$ sodium hydroxide aqueous solution were added to the liquid phenol. The solution was stirred for $15 \mathrm{~min}$ (with a KPG stirrer). After adding $5.6 \mathrm{~mL}$ of formalin (37 wt \% formaldehyde) and further stirring for $5 \mathrm{~min}, 9.59 \mathrm{~g}$ of ground silica template were added. The mixture was heated to $75^{\circ} \mathrm{C}$ and stirred for $1.5 \mathrm{~h}$. The polymer/silica composite was dried in vacuum and polymerized in an oven at $100{ }^{\circ} \mathrm{C}$ for $24 \mathrm{~h}$. The particles were washed with water and dried at $60^{\circ} \mathrm{C}$. Carbonization was carried out in a tubular furnace under argon atmosphere in two steps: The sample was heated to $350{ }^{\circ} \mathrm{C}$ for $5 \mathrm{~h}$ (heating rate: $1{ }^{\circ} \mathrm{C} / \mathrm{min}$ ) and $900{ }^{\circ} \mathrm{C}$ for $2 \mathrm{~h}$ (heating rate: $5{ }^{\circ} \mathrm{C} / \mathrm{min}$ ). The silica template was removed by washing with hydrofluoric acid $(10 \%)$. The samples were washed with deionized water and ethanol and dried at $100{ }^{\circ} \mathrm{C}$. The removal of the silica template was assured by thermal combustion of the carbon in air. The template was considered removed when the residual mass was less than $2 \mathrm{wt} \%$.

\section{Preparation of carbon/sulfur composites}

Carbon/sulfur composites were prepared in four different ways.

1. Melt impregnation: HCS and sulfur were ground together in distinct weight ratios, sealed in a flask and heated to $155^{\circ} \mathrm{C}$ for $12 \mathrm{~h}$.

2. Melt impregnation in vacuum: HCS and sulfur were ground together in distinct weight ratios, sealed in a flask, evacuated to a pressure of $1.1 \cdot 10^{-4}$ bar and heated to $125^{\circ} \mathrm{C}$ for $12 \mathrm{~h}$ at this pressure.

3. Melt impregnation under pressure: HCS and sulfur were ground together in distinct weight ratios and placed in a Teflon lined steel autoclave filled to $90 \%$ capacity with water. The autoclave was sealed and the sample was heated to $155^{\circ} \mathrm{C}$ for $12 \mathrm{~h}$. This temperature and degree of filling with water creates a pressure of approximately 7 bar (measured by heating water in a microwave and monitoring the resulting pressure).

4. Impregnation from solution: HCS were ground for several minutes with a $0.62 \mathrm{M}$ solution of sulfur in carbon disulfide. The volume of solution was chosen in accordance to the absolute pore volume of the applied amount of carbon. After drying the composite at room temperature the procedure was repeated until the desired amount of sulfur was achieved.

\section{Electrode processing, cell assembling and electrochemical testing}

A mixture of the carbon/sulfur composite powder (83 wt \%), Super C65 (Timcal, 6 wt \%), Printex XE2 (Orion, 6 wt \%) and poly(vinyl alcohol) Selvol 425 (Sekisui, 5 wt \%) in water, isopropanol and 1-methoxy-2-propanol (65:30:5 weight ratio) was prepared to form a homogeneous slurry. The slurry coating and drying procedure are described elsewhere $[47,48]$. 50-60 $\mu \mathrm{m}$ thick electrodes with a sulfur loading of approx. $2.0 \mathrm{mg} \cdot \mathrm{cm}^{-2}$ were used for testing. Sulfur cathode, polyethylene membrane (Toray Tonen, $15 \mathrm{~mm}$ ) and lithium foil (Chemetall Foote Corp., $50 \mu \mathrm{m}$ ) were assembled in coin-type cells inside an argon-filled glovebox from MBraun. The electrolyte used was a solution of lithium bis(trifluoromethanesulfonyl)imide (Aldrich, 99.95\%, 8 wt \%), lithium nitrate (Merck, 99.995\%, 4 wt \%), 1,2-dimethoxyethane (Alfa Aesar, $>99 \%, 44 \mathrm{wt} \%$ ), and 1,3-dioxolane (Acros, 99.8\%, 44 wt \%). The volume of electrolyte used in the cell was $10 \mu \mathrm{L} / \mathrm{mg}_{\text {sulfur }}$. Galvanostatic measurements were performed at $25{ }^{\circ} \mathrm{C}$ in the potential range of $2.5-1.7 \mathrm{~V}$ versus $\mathrm{Li} / \mathrm{Li}^{+}$using a MACCOR Series 4000 (Tulsa, Oklahoma) multichannel battery cycler. A constant voltage step was applied at the end of charging until a current drop of $90 \%$ was achieved. Capacity values in the manuscript were calculated on the basis of the sulfur mass. After the formation cycle at a $\mathrm{C} / 50$ rate (with $1 \mathrm{C}=$ $1672 \mathrm{~mA} / \mathrm{g}_{\text {sulfur }}$ ) was completed, the cells were charged and discharged at $\mathrm{C} / 5$.

\section{Characterization methods}

Dynamic light scattering was measured with a Malvern Nano ZS using a HeNe gas laser with a wavelength of $633 \mathrm{~nm}$.

X-ray diffraction patterns were recorded with a PANalytical X'Pert Pro MPD using $\mathrm{Cu} \mathrm{K} \alpha$ radiation $(\lambda=1.5406 \AA, 45 \mathrm{kV}$, $40 \mathrm{~mA})$.

Thermogravimetric measurements of the samples were carried out on a Netzsch STA 409 at a heating rate of $5{ }^{\circ} \mathrm{C} / \mathrm{min}$ in air.

Nitrogen physisorption measurements were performed on a Quantachrome Quadrasorb-SI-MP instrument at 77.4 K. Pore size distributions were calculated from the adsorption branch by a non-local density functional theory (NLDFT) model assuming cylindrical pores for silica samples and by a quenched solid density functional theory model assuming slit pores for pores smaller than $2 \mathrm{~nm}$ and cylindrical pores for pores larger than $2 \mathrm{~nm}$ for carbon samples. The specific surface area was calculated from the adsorption branch in a relative pressure interval from 0.07 to 0.30 by the BET method. Carbon dioxide physisorption was conducted on a Quantachrome Autosorb-iQ-MP instrument at $273.15 \mathrm{~K}$. The pore size distribution was calcu- 
lated by an NLDFT model assuming slit pores with a moving point average of three. Degassing prior to the physisorption measurements was carried out in vacuum at $120^{\circ} \mathrm{C}$ for $20 \mathrm{~h}$ for carbon samples and at room temperature for $20 \mathrm{~h}$ for carbon/ sulfur composites.

Scanning electron microscopy images were taken on a Zeiss Leo 1525 microscope operated at $5 \mathrm{kV}$ and $20 \mathrm{kV}$ for EDX analysis. A carbon layer of approximately $20 \mathrm{~nm}$ was deposited onto the samples prior to EDX measurements.

Transmission electron microscopy was carried out using a JEOL JEM 2200 FS operated at $200 \mathrm{kV}$.

Raman spectra were recorded on a Bruker Senterra Raman microscope $(\lambda=532 \mathrm{~nm}, P=2 \mathrm{~mW})$.

\section{Supporting Information}

Supporting Information contains characterization of the silica template (SEM, pXRD, nitrogen physisorption), $\mathrm{CO}_{2}$ physisorption of HCS as well as thermal analysis, SEM/EDX analysis and nitrogen physisorption of $\mathrm{HCS} /$ sulfur composites and derivation of Equation 3 and Equation 4.

\section{Supporting Information File 1}

Additional Information.

[http://www.beilstein-journals.org/bjnano/content/

supplementary/2190-4286-7-114-S1.pdf]

\section{Acknowledgements}

We thank Dr. Frank Hoffmann and Carl-Philipp Elverfeldt for helpful discussions and proof reading as well as Renate Walter for SEM and EDX measurements. This research was supported by the BASF International Scientific Network for Electrochemistry and Batteries.

\section{References}

1. Tarascon, J.-M.; Armand, M. Nature 2001, 414, 359-367. doi:10.1038/35104644

2. Aricò, A. S.; Bruce, P.; Scrosati, B.; Tarascon, J.-M.; van Schalkwijk, W. Nat. Mater. 2005, 4, 366-377. doi:10.1038/nmat1368

3. Bruce, P. G.; Scrosati, B.; Tarascon, J.-M. Angew. Chem., Int. Ed. 2008, 47, 2930-2946. doi:10.1002/anie.200702505

4. Bruce, P. G.; Freunberger, S. A.; Hardwick, L. J.; Tarascon, J.-M. Nat. Mater. 2011, 11, 19-29. doi:10.1038/nmat3191

5. Scrosati, B.; Garche, J. J. Power Sources 2010, 195, 2419-2430. doi:10.1016/j.jpowsour.2009.11.048
6. Ji, X.; Nazar, L. F. J. Mater. Chem. 2010, 20, 9821-9826. doi:10.1039/b925751a

7. Yamin, H.; Gorenshtein, A.; Penciner, J.; Sternberg, Y.; Peled, E. J. Electrochem. Soc. 1988, 135, 1045-1048. doi:10.1149/1.2095868

8. Cheon, S.-E.; Ko, K.-S.; Cho, J.-H.; Kim, S.-W.; Chin, E.-Y.; Kim, H.-T. J. Electrochem. Soc. 2003, 150, A796-A799. doi:10.1149/1.1571532

9. Cheon, S.-E.; Ko, K.-S.; Cho, J.-H.; Kim, S.-W.; Chin, E.-Y.; Kim, H.-T. J. Electrochem. Soc. 2003, 150, A800-A805. doi:10.1149/1.1571533

10. Shim, J.; Striebel, K. A.; Cairns, E. J. J. Electrochem. Soc. 2002, 149, A1321-A1325. doi:10.1149/1.1503076

11. Mikhaylik, Y. V.; Akridge, J. R. J. Electrochem. Soc. 2004, 151, A1969-A1976. doi:10.1149/1.1806394

12. Haynes, W. M., Ed. CRC Handbook of Chemistry and Physics; CRC Press: Boca Raton, 2015.

13. Ji, L.; Rao, M.; Aloni, S.; Wang, L.; Cairns, E. J.; Zhang, Y. Energy Environ. Sci. 2011, 4, 5053-5059. doi:10.1039/c1ee02256c

14. Elazari, R.; Salitra, G.; Garsuch, A.; Panchenko, A.; Aurbach, D. Adv. Mater. 2011, 23, 5641-5644. doi:10.1002/adma.201103274

15. Han, S.-C.; Song, M.-S.; Lee, H.; Kim, H.-S.; Ahn, H.-J.; Lee, J.-Y. J. Electrochem. Soc. 2003, 150, A889-A893. doi:10.1149/1.1576766

16. Yuan, L.; Yuan, H.; Qu, X.; Chen, L.; Zhu, W. J. Power Sources 2009, 189, 1141-1146. doi:10.1016/j.jpowsour.2008.12.149

17. Wang, J.-Z.; Lu, L.; Choucair, M.; Stride, J. A.; Xu, X.; Liu, H.-K. J. Power Sources 2011, 196, 7030-7034. doi:10.1016/j.jpowsour.2010.09.106

18. Wang, H.; Yang, Y.; Liang, Y.; Robinson, J. T.; Li, Y.; Jackson, A.; Cui, Y.; Dai, H. Nano Lett. 2011, 11, 2644-2647. doi:10.1021/nl200658a

19. Ji, L.; Rao, M.; Zheng, H.; Zhang, L.; Li, Y.; Duan, W.; Guo, J.; Cairns, E. J.; Zhang, Y. J. Am. Chem. Soc. 2011, 133, 18522-18525. doi:10.1021/ja206955k

20. Wang, J. L.; Yang, J.; Xie, J. Y.; Xu, N. X.; Li, Y. Electrochem. Commun. 2002, 4, 499-502. doi:10.1016/S1388-2481(02)00358-2

21. Ji, X.; Lee, K. T.; Nazar, L. F. Nat. Mater. 2009, 8, 500-506. doi:10.1038/nmat2460

22. Chen, S.-R.; Zhai, Y.-P.; Xu, G.-L.; Jiang, Y.-X.; Zhao, D.-Y.; Li, J.-T.; Huang, L.; Sun, S.-G. Electrochim. Acta 2011, 56, 9549-9555. doi:10.1016/j.electacta.2011.03.005

23. Jayaprakash, N.; Shen, J.; Moganty, S. S.; Corona, A.; Archer, L. A. Angew. Chem., Int. Ed. 2011, 50, 5904-5908. doi:10.1002/anie.201100637

24. He, G.; Evers, S.; Liang, X.; Cuisinier, M.; Garsuch, A.; Nazar, L. F. ACS Nano 2013, 7, 10920-10930. doi:10.1021/nn404439r

25. Zhang, C.; Wu, H. B.; Yuan, C.; Guo, Z.; Lou, X. W. D. Angew. Chem., Int. Ed. 2012, 51, 9592-9595. doi:10.1002/anie.201205292

26. Böttger-Hiller, F.; Kempe, P.; Cox, G.; Panchenko, A.; Janssen, N.; Petzold, A.; Thurn-Albrecht, T.; Borchardt, L.; Rose, M.; Kaskel, S.; Georgi, C.; Lang, H.; Spange, S. Angew. Chem., Int. Ed. 2013, 52, 6088-6091. doi:10.1002/anie.201209849

27. Wang, Z.; Li, X.; Cui, Y.; Yang, Y.; Pan, H.; Wang, Z.; Qian, G. J. Electrochem. Soc. 2014, 161, A1231-A1235. doi:10.1149/2.0341409jes

28. Liu, S.; Xie, K.; Chen, Z.; Li, Y.; Hong, X.; Xu, J.; Zhou, L.; Yuan, J.; Zheng, C. J. Mater. Chem. A 2015, 3, 11395-11402. doi:10.1039/C5TA00897B

29. Zhou, W.; Xiao, X.; Cai, M.; Yang, L. Nano Lett. 2014, 14, 5250-5256. doi:10.1021/nl502238b 
30. Zhou, W.; Wang, C.; Zhang, Q.; Abruña, H. D.; He, Y.; Wang, J.; Mao, S. X.; Xiao, X. Adv. Energy Mater. 2015, 5, 1401752. doi:10.1002/aenm.201401752

31. Zhou, G.; Zhao, Y.; Manthiram, A. Adv. Energy Mater. 2015, 5, 1402263. doi:10.1002/aenm.201402263

32. Raiß, C.; Peppler, K.; Janek, J.; Adelhelm, P. Carbon 2014, 79, 245-255. doi:10.1016/j.carbon.2014.07.065

33. Haffer, S.; Tiemann, M.; Fröba, M. Chem. - Eur. J. 2010, 16 , 10447-10452. doi:10.1002/chem.201000643

34. Yoon, S. B.; Kim, J.-Y.; Kim, J. H.; Park, Y. J.; Yoon, K. R.; Park, S.-K.; Yu, J.-S. J. Mater. Chem. 2007, 17, 1758-1761. doi:10.1039/b617471j

35. Stöber, W.; Fink, A.; Bohn, E. J. Colloid Interface Sci. 1968, 26, 62-69. doi:10.1016/0021-9797(68)90272-5

36. Fujimoto, H. Carbon 2003, 41, 1585-1592. doi:10.1016/S0008-6223(03)00116-7

37. Li, Z. Q.; Lu, C. J.; Xia, Z. P.; Zhou, Y.; Luo, Z. Carbon 2007, 45, 1686-1695. doi:10.1016/j.carbon.2007.03.038

38. Pimenta, M. A.; Dresselhaus, G.; Dresselhaus, M. S.; Cançado, L. G.; Jorio, A.; Saito, R. Phys. Chem. Chem. Phys. 2007, 9, 1276-1290. doi:10.1039/B613962K

39. Thommes, M.; Kaneko, K.; Neimark, A. V.; Olivier, J. P.; Rodriguez-Reinoso, F.; Rouquerol, J.; Sing, K. S. W. Pure Appl. Chem. 2015, 87, 1051-1069. doi:10.1515/pac-2014-1117

40. Wang, J.; Liu, L.; Ling, Z.; Yang, J.; Wan, C.; Jiang, C. Electrochim. Acta 2003, 48, 1861-1867. doi:10.1016/S0013-4686(03)00258-5

41. Balakumar, K.; Kalaiselvi, N. RSC Adv. 2015, 5, 34008-34018. doi:10.1039/C5RA01436K

42. Dong, Y.; Liu, S.; Wang, Z.; Liu, Y.; Zhao, Z.; Qiu, J. Nanoscale 2015, 7, 7569-7573. doi:10.1039/C5NR01015B

43. Li, C.; Yin, L. Part. Part. Syst. Charact. 2015, 32, 756-763. doi:10.1002/ppsc.201400259

44. Jozwiuk, A.; Sommer, H.; Janek, J.; Brezesinski, T. J. Power Sources 2015, 296, 454-461. doi:10.1016/j.jpowsour.2015.07.070

45. Yoon, S. B.; Sohn, K.; Kim, J. Y.; Shin, C.-H.; Yu, J.-S.; Hyeon, T. Adv. Mater. 2002, 14, 19-21. doi:10.1002/1521-4095(20020104)14:1<19::AID-ADMA19>3.0.CO;2-X

46. Meng, Y.; Gu, D.; Zhang, F.; Shi, Y.; Yang, H.; Li, Z.; Yu, C.; Tu, B.; Zhao, D. Angew. Chem., Int. Ed. 2005, 44, 7053-7059. doi:10.1002/anie.200501561

47. Schneider, A.; Weidmann, C.; Suchomski, C.; Sommer, H.; Janek, J.; Brezesinski, T. Chem. Mater. 2015, 27, 1674-1683. doi:10.1021/cm504460p

48. Kulisch, J.; Sommer, H.; Brezesinski, T.; Janek, J. Phys. Chem. Chem. Phys. 2014, 16, 18765-18771. doi:10.1039/C4CP02220C

\section{License and Terms}

This is an Open Access article under the terms of the Creative Commons Attribution License (http://creativecommons.org/licenses/by/4.0), which permits unrestricted use, distribution, and reproduction in any medium, provided the original work is properly cited.

The license is subject to the Beilstein Journal of Nanotechnology terms and conditions: (http://www.beilstein-journals.org/bjnano)

The definitive version of this article is the electronic one which can be found at:

doi:10.3762/bjnano.7.114 